\title{
Demographic, Epidemiological and Etiological Characteristics of Fungal Keratitis Cases in Southern Anatolia Tertiary Eye Care Center
}

\author{
Ayse idil cakmak ( $\square$ idilayse@yahoo.com ) \\ Meryem Çetin \\ Amasya University: Amasya Universitesi \\ Yasemin Öz \\ Osmangazi University: Eskisehir Osmangazi Universitesi \\ Necip Kara \\ Gaziantep Universitesi Tip Fakultesi
}

Mustafa Kemal Universitesi: Hatay Mustafa Kemal Universitesi https://orcid.org/0000-0003-4377-7314

\section{Research Article}

Keywords: Fungal keratitis, ocular microbiology, fusarium, aspergillus, candida

Posted Date: August 11th, 2021

DOI: https://doi.org/10.21203/rs.3.rs-396138/v1

License: (c) (-) This work is licensed under a Creative Commons Attribution 4.0 International License. Read Full License 


\section{Abstract}

Purpose: To evaluate the demographic, epidemiological and etiological features of cases with fungal keratitis seen at a tertiary eye care center in Southern Anatolia.

Materials and Methods: A retrospective review of all culture-proven fungal keratitis seen from May 2017 to May 2019 was evaluated. The demographic characteristics of the patients, epidemiological factors and etiological factors of the cases were noted.

Results: The mean age of 15 cases with fungal keratitis was $46 \pm 7$ years (ranging 19-77 years) with a maleto- female ratio of $4: 1$. The majority of the occupation of the cases were mostly agricultural workers or farmers (73\%). The etiology was predominantly trauma mostly with an enviroment origin (93.3\%). Fungal growth was detected in 15 eyes (38.5\%) in a total of 39 microbial positive corneal cultures. Filamentous fungi were responsible for all cases, including Fusarium sp. in 8 eyes (53.3\%) and Aspergillus sp. in 7 eyes (46.7\%). Species of Fusarium were determined in 4 eyes, namely F. Aquaeductus, F. Chlamydosporum, F. oxysporum and F. solani; whereas species of Aspergillus were determined in 3 eyes, namely $A$. niger and $A$. flavus. Bacterial and fungal coinfection was shown in two eyes (Aspergillus sp. with Gram (+) beta hemolytic streptococcus; Fusarium sp. with Pseudomonas orzyihabitans).

Conclusion: Agricultural activity and associated eye trauma were shown to be the main causes of fungal keratitis in which filamentous fungi were isolated in all cases. The identified etiological factors may be useful in the selection of early empirical treatment of fungal keratitis cases encountered in Southern Anatolia.

\section{Introduction}

Fungal keratitis, also known for keratomycosis, is the inflammation of the cornea that results from fungal infection. It accounts for more than $50 \%$ of cases with infectious keratitis, in especially tropical areas of the world [1-4]. Typical pesentation consists of suppurative and ulcerative lesions, which may progress to corneal perforations if the stromal inflammation is not taken under control $[5,6]$. Classification of fungi causing keratitis has been made according to genera basicly in two groups, which are filamentous fungi and yeast or yeast-like fungi $[7,8]$.

Epidemiological studies have shown that filamentous fungi particularly due to Fusarium sp., Aspergillus sp. and Curvularia sp. are the principal causes of mycotic keratitis throughout the world. They are more common in tropical and subtropical regions; whereas yeasts like Candida $s p$. are mostly isolated in regions with temperate climate $[9,10]$.

The aim of this study is to evaluate the demographic, epidemiological and etiological characteristics of cases with fungal keratitis in a tertiary care center of South Anatolia located in the Eastern Mediterranean region.

\section{Methods}


The design of the study was retrospective and cross-sectional that was conducted in accordance with the principals of the Declaration of Helsinki. Approval was obtained from the University Research and Ethics Committee. The files of 39 patients who applied to the tertiary eye care center with corneal ulcer between May 2017 and May 2019 were reviewed and analyzed.

The demographic features, predisposing factors, associated systemic and ocular characteristics, and microbiological analysis results of cases diagnosed with fungal keratitis were evaluated. Patients with viral keratitis, bacterial keratitis and neurotrophic keratitis, and patients with corneal ulcers that did not show any fungi in cytological samples were excluded from the study.

\section{Microbiological Investigations:}

The base and edges of corneal ulcers were scrapped by a spatula under local anesthesia. Microscopical examination was performed for all corneal scraping specimens after staining by Gram, Giemsa, and calcofluor white with $10 \%$ potassium hydroxide. A part of each specimen was also inoculated onto blood agar, brain-heart infusion agar and Sabouraud glucose-neopepton agar plates which were incubated for up to 6 weeks at $30 \circ \mathrm{C}$ and $37 \circ \mathrm{C}$ under appropriate atmospheric conditions [11]. All culture plates were examined daily for fungal or bacterial growth. Fungal growth in culture was deemed significant if:

1. this correlated with the clinical presentation, or

2. growth of the same fungus was demonstrated on two or more solid culture media in the absence of fungus in smears, or

3. there was semiconfluent growth at the site of inoculation on one solid medium, or

4. there was growth in the liquid media, consistent with microscopy [11].

Re-scraping was performed in case of insufficient material, or suspicion of contaminated material, or adverse results unrelated to clinical properties. After growth on media the isolated fungi were identified according to their macroscopic and microscopic features. The identification of filamentous fungal colonies was made by conventional methods; microscopically (features of conidiogenous cells and conidiophores, production, morphology and organization of conidia, macro-microconidia and blastoconidia, presence or absence of chlamydospores) and macroscopically (structures and colors of colonies) morphological characteristics, rates and temperatures of growth, etc. [12]. Antibiotic susceptibility testing was performed according to CLSI M38-A2, broth microdilution method for molds.

\section{Results}

We identified 39 cases with culture positive microbial keratitis, where a fungal cause was isolated from corneal scraping samples of 15 eyes (38.5\%) of 15 cases. Hyphae were observed in 17 samples out of 17 cases with keratitis on microscopy; however, no fungal growth was shown in two. The remainder were cases of bacterial keratitis (61.5\%).

The age of cases with microbiologically proven fungal keratitis ranged from 19 to 77 years with a mean of $46 \pm 7$ years. Of the 15 patients, $12(80 \%)$ were men and the male / female ratio was $12: 3$. There were 1 
scrap seller (6.7\%), 1 undergraduate student (6.7\%), 2 construction workers (13.3\%) and 11 agricultural workers (9 agricultural workers and 2 farm owners) (73.3\%). Corneal contact with a herbal material was recorded in 10 cases; the others were soil in 4 patients; lime powder in 1 patient and a metal rod in 1 patient. The undergraduate student who had a history of scratching her eyes while working in a garden was the only case who wore soft contact lenses. None of the cases had a previous history of topical or systemic steroid use.

The genera isolated were Aspergillus in 7 eyes (47\%) and Fusarium in 8 eyes (53\%). Among the Fusarium species isolated cases, F. Aquaeductus, F. Chlamydosporum, F. oxysporum and F. solani were detected from 4 samples (Fig. 1). Among the Aspergillus species, A. niger (2 samples) and A. flavus (1 sample) were detected. The demographic, etiological characteristics and microbiological spectrum of fungal keratitis cases are shown in Table 1. 
Table 1

The demographics, epidemiological and etiological features of the fungal keratitis cases

\begin{tabular}{|c|c|c|c|c|}
\hline $\begin{array}{l}\text { Age / } \\
\text { Gender }\end{array}$ & Occupation & $\begin{array}{l}\text { Eye } \\
\text { contact }\end{array}$ & Associated conditions & Fungus \\
\hline $20 / F$ & $\begin{array}{l}\text { Undergrad- } \\
\text { gardening }\end{array}$ & soil & Soft contact lens use & Aspergillus sp. \\
\hline $57 / M$ & $\begin{array}{l}\text { Agricultural } \\
\text { worker }\end{array}$ & tree branch & Diabetes mellitus & Aspergillus sp. \\
\hline 55 / M & $\begin{array}{l}\text { Agricultural } \\
\text { laborer }\end{array}$ & onion skin & - & Aspergillus sp. \\
\hline $51 / F$ & $\begin{array}{l}\text { Agricultural } \\
\text { worker }\end{array}$ & tree branch & Diabetes mellitus & Aspergillus sp.* \\
\hline $35 / M$ & $\begin{array}{l}\text { Agricultural } \\
\text { worker }\end{array}$ & tree branch & - & Aspergillus niger \\
\hline 77 / M & Farmer & leaf & Pseudophakia & Aspergillus niger \\
\hline $32 / M$ & $\begin{array}{l}\text { Agricultural } \\
\text { worker }\end{array}$ & soil & Keratoplasty & Aspergillus flavus \\
\hline $50 / M$ & $\begin{array}{l}\text { Agricultural } \\
\text { worker }\end{array}$ & tree branch & $\begin{array}{l}\text { Diabetes mellitus, } \\
\text { hypertension, stroke }\end{array}$ & Fusarium oxysporium \\
\hline $57 / M$ & $\begin{array}{l}\text { Agricultural } \\
\text { worker }\end{array}$ & tree branch & - & $\begin{array}{l}\text { Fusarium } \\
\text { chlamydosporum }\end{array}$ \\
\hline $38 / M$ & $\begin{array}{l}\text { Agricultural } \\
\text { worker }\end{array}$ & tree branch & - & $\begin{array}{l}\text { Fusarium } \\
\text { aquaeductum }\end{array}$ \\
\hline $19 / \mathrm{M}$ & $\begin{array}{l}\text { Agricultural } \\
\text { worker }\end{array}$ & bush & - & Fusarium solani \\
\hline 70 / F & Farmer & tree branch & - & Fusarium sp. \\
\hline 49 / M & $\begin{array}{l}\text { Construction } \\
\text { worker }\end{array}$ & metal rod & - & Fusarium sp. \\
\hline $25 / M$ & $\begin{array}{l}\text { Construction } \\
\text { worker }\end{array}$ & $\begin{array}{l}\text { lime } \\
\text { powder }\end{array}$ & - & Fusarium sp. \\
\hline $50 / M$ & Scrap dealer & $\begin{array}{l}\text { wooden } \\
\text { object }\end{array}$ & - & Fusarium sp. ${ }^{\dagger}$ \\
\hline \multicolumn{5}{|c|}{ M: male; F: Female } \\
\hline \multicolumn{5}{|c|}{ * Fungal keratitis coinfected with gram(+) beta hemolytic streptococci. } \\
\hline
\end{tabular}

Antibiotic susceptibility testing of the identified species are given in Table 2. In vitro test results of Caspofungin and Anidulafungin MIC values against Aspergillus sp. (especially A. flavus) were found to be 
very low. On the other hand, they were found high against Fusarium sp. in general (especially $F$. Aquaeductum).

Table 2

Broth microdilution antifungal susceptibility testing results.

\begin{tabular}{|c|c|c|c|c|c|}
\hline \multirow[t]{2}{*}{ Isolates } & \multicolumn{5}{|c|}{ MIC values of antifungal drugs $(\mu \mathrm{g} / \mathrm{mL})$} \\
\hline & AmphotericinB & Voriconazole & Posaconazole & Caspofungin & Anidulafungin \\
\hline A. flavus & 1.5 & 0.5 & 0.5 & 0.064 & 0.003 \\
\hline A. niger -1 * & $0.12 \mathrm{~g} / \mathrm{L}$ & 1 & 0.06 & $\leq 0.03$ & $\leq 0.03$ \\
\hline A. niger $-2^{+}$ & $0.25 \mathrm{~g} / \mathrm{L}$ & 0.5 & 0.06 & $\leq 0.03$ & $\leq 0.03$ \\
\hline F.aquaeductum & 1 & 1 & $>16$ & 16 & $>16$ \\
\hline F.chlamydosporum & 2 & 4 & $>16$ & 16 & 2 \\
\hline F.oxysporum & 0.25 & 8 & $>16$ & 4 & 1 \\
\hline F. solani & 16 & 8 & $>16$ & 16 & 16 \\
\hline \multicolumn{6}{|c|}{ A. Aspergillus; F. Fusarium } \\
\hline \multicolumn{6}{|c|}{ * A. niger-1: identified from the corneal sample of the 35-year- old male } \\
\hline
\end{tabular}

Bacterial and fungal coinfection was shown in two eyes (13.3\%). Aspergillus sp. and Gram (+) beta hemolytic streptococci co-infection was detected in a 51-year-old diabetic agricultural worker who was admitted to the hospital with a diagnosis of both keratitis and endophthalmitis with findings of proliferative diabetic retinopathy observed on fundoscopy. The other was Fusarium sp. and Pseudomonas oryzihabitans coinfection detected in a 50-year-old male. He was a scrap dealer with a corneal ulcer injured by a wooden object.

Among the known systemic factors, diabetes mellitus type II was reported in three patients (20\%). A history of hypertension and stroke was determined in a 50-year-old diabetic male agricultural worker. Two patients had previous ocular surgery (13\%). One of them was a 77-year-old rancher who had bilateral cataract surgery for senile cataracts 6 years ago. His right cornea was injured by an orange leaf from which Aspergillus niger was isolated. The other was an agricultural worker who had penetrating keratoplasty due to trauma 5 years ago. He had a history of soil-related corneal injury while working in a cotton field. Aspergillus flavus was isolated from the patient's corneal sample. (Fig. 1)

\section{Discussion}

The results of this study covering a period of two years showed that filamentous fungi were the main etiology in cases with fungal keratitis. Fusarium was the most isolated filamentous fungus, followed by Aspergillus. In addition, most cases had been associated with outdoor activities, where trauma with a herbal 
substance was the leading susceptibility factor, with structural materials in the second place. It has also been observed that men were significantly more affected than women.

Epidemiological studies have shown that the microorganisms that cause keratitis may vary according to the geographical features and climatic conditions of the countries. Filamentous fungi are the predominant pathogens that have been widely proven to be associated with fungal keratitis in humid and warm climates [1,13-14]. Provinces of Southern Anatolia are located in the far east of the Mediterranean coast [15]. The climate here is Mediterranean, characterized by hot and humid summers and humid subtropical climate ranging from cold to mild winters [16]. The main pillars of the economy in this region are agriculture and industry [17].

Most of the patients in this study were agricultural workers, predominantly male, and corneal trauma with an herbal substance was the most common cause of keratitis. Studies have reported that ocular trauma is the predominant risk factor for fungal keratitis [18-21]. In a 10-year study by Gopinathan et al, it was found that males were affected 2.5 times more than females, and trauma was the etiological factor in more than $50 \%$ of infected eyes [11]. Corneal trauma with an organic or herbal substance has been considered the predominant predisposing factor affecting $40-60 \%$ of patients with mycotic keratitis [7, 8, 22-24]. In line with these facts, Bharathi et al noted in a retrospective review that the highest prevalence of culture-proven cases of fungal keratitis was observed during the South Indian harvest season between June and September [20]. They determined that $92 \%$ of patients with fungal keratitis had ocular trauma and $61 \%$ of cases were injured by a herbal substance.

In the etiology of corneal damage that causes keratomycosis, leaves, rice grain, cow tail, tree branch, soil and metal objects have been described in various studies [20-27]. Similarly, Ebadollahi-Natanzi et al found that corneal ulcers caused by fungal microorganisms are most common among farmers and construction workers in rural, structural, and roofless areas [28]. In parallel with various studies in the literature, it has been reported that men over the age of 15 , especially those working outdoors, are more frequently affected $[13,14$, $21,28-31]$. Also, in regions where agriculture is the main economy, the highest fungal keratitis is analyzed to be associated with Fusarium and Aspergillus species [28].

Filamentous fungi, inhabitants of the environment, are widely associated with keratitis caused by ocular trauma, especially in topical areas containing organic matter $[1,13,14]$. In some countries with tropical or subtropical regions such as Singapore, Hong Kong, China, East India, South Florida, East Africa, and Northern Tanzania, the filamentous species were mostly isolated fungi and it was Fusarium sp. identified as the primary cause, followed by Aspergillus sp [19, 20,30-37]. Similarly, studies from Ghana, Australia, Iran, Brazil, Tunisia, Thailand, Taiwan, Northern China and South India found Fusarium to be the most commonly identified species isolated from fungal keratitis cases. On the other hand, studies from India and the rest of Bangladesh showed that Aspergillus sp. was the major species detected in cases of fungal keratitis [6].

This study supports the existing data obtained from studies conducted in other regions of Anatolia where geographical and demographic factors are similar. In a study conducted in a province of Southern Anatolia, 11 out of 20 fungal keratitis cases had a history of trauma due to plant or soil material [38]. In this 3-year retrospective study, there were five patients with a previous history of topical steroid use, but similarly, the 
cases were predominantly male, and filamentous pathogens were seen in the microscopy of all corneal scrapings.

According to the results of a 16-year retrospective study conducted in Western Anatolia where etiological factors and clinical features of microbial keratitis were investigated, almost half of the eyes had a history of ocular trauma with a herbal substance and the fungal pathogens isolated from these traumatized eyes were predominantly filamentous and $43.5 \%$ of fungal keratitis cases were agricultural workers or farmers [39]. Fusarium $s p$ were identified as the most isolated fungal species but differently they were followed by Candida sp. In addition, unlike our study, it was determined that corticosteroid therapy was the second most common risk factor for fungal keratitis.

It has been shown that fungal infections show a geographical distribution depending on climate and agricultural conditions [11]. It has been reported that yeast infections causing fungal keratitis are more common in temperate climates and are less associated with vegetative matter and trauma, unlike filamentous fungi. In a large analysis conducted in New York, Candida sp. was found to be the most common fungal agent (48\%) among 5083 cases with keratitis [40]. Ocular surface diseases such as dry eye syndrome and corneal ulcer, systemic immunosuppressive diseases such as diabetes mellitus and the use of steroids and broad-spectrum antibiotics have been shown to be important predisposing factors for Candida-induced keratitis $[1,13,14,40]$. In addition, previous ocular surgeries, especially penetrating keratoplasty, a preexisting epithelial defect due to herpes keratitis and contact lens abrasions have been also found as risk factors for Candida keratitis [1, 40,41]. In the present study, there were cases with diabetis mellitus, previous history of ocular surgery and contact lens use, however, Candida sp. was not isolated from any of them It may be because all cases had a history of corneal contact with an environmental agent.

There are extensive retrospective studies defining contact lens use as an important predisposing risk factor for fungal keratitis in studies where fungal etiologies differ by species [14, 32-35, 42, 43]. Filamentous fungus have been reported as one of these etiological factors for contact lens-associated keratitis [44-46]. In this study, Aspergillus sp. grew up in a corneal scraping culture of a case using contact lenses and she had a history of scratching her eye while working in a garden. Wong et al. reported that there were 2 patients using contact lenses among fungal keratitis cases. In this 5-year hospital-based retrospective study, the researchers determined the microbial and clinical characteristics of cases with fungal keratitis in Singapore, where the climate is warm and tropical. Similar to the current study, more than half of the patients had trauma and Fusarium sp. was the leading cause of fungal keratitis, followed by Aspergillus [47].

The most significant limitations of the present study were the retrospective design and relatively small number of patients. In addition, there were cases where subspecies could not be detected. Adding to this, the inclusion of only culture-positive cases of fungal keratitis may have led to a biased prevalence. That is, there may be some patients with high suspicion of fungal keratitis where fungal growth was not demonstrated in cultures of corneal specimens and microbiological studies were not repeated enough. Furthermore, although important information was provided to guide the treatment of fungal keratitis, the clinical picture, treatment methods and responses to these treatments were not included due to the lack of follow-up information of the patients [48]. For his reason, the current study chose to focus more on the demographic features, epidemiological characteristics and etiological factors of the cases with fungal keratitis. 
Our study, despite all its limitations, provides reliable preliminary information on this subject in Southern Anatolia, showing that agricultural activity and associated eye trauma are the main cause of fungal keratitis caused by filamentous fungi. The results of this retrospective review can be useful for both the prevention and early diagnosis of fungal keratitis, as corneal infections need urgent recognition to prevent permanent vision loss by facilitating a complete recovery [49]. Furthermore these identified etiological factors may be useful in the selection of early empirical treatment of fungal keratitis cases encountered in Southern Anatolia.

\section{Declarations}

\section{Author contributions}

AIC and $\mathrm{MC}$ and $\mathrm{YO}$ contributed to writing original draft preparation; $\mathrm{AIC}$ and NK contributed to conceptualization; AIC and NK contributed to formal analysis and investigation; AIC and MC contributed to methodology; AIC and MC and YO contributed to writing-review and editing; AIC and NK contributed to the provision of resources; AIC, and MC contributed to supervision.

\section{Funding}

No funding was received to assist with the preparation of this manuscript

\section{Conflict of interest}

The authors have no conflicts of interest to declare that are relevant to the content of this article.

\section{Ethical Approval}

All procedures in studies involving human participants were performed in accordance with the ethical standards of the institutional and national research committee and with the 1964 Helsinki Declaration and its later amendments or comparable ethical standards (ethics committee approval date-decision number: 23/05/2019-10).

\section{Informed Consent}

Informed consent was obtained from all individual participants included in the study.

\section{References}

1. Kredics L, Narendran V, Shobana CS, Vágvölgyi C, Manikandan P, Indo-Hungarian Fungal Keratitis Working Group (2015) Filamentous fungal infections of the cornea: a global overview of epidemiology and drug sensitivity. Mycoses 58:243-260

2. Sharma S, Srinivasan M, George C (1993) The current status of Fusarium species in mycotic keratitis in south India. Indian J Med Microbiol 11:140-147 
3. Srinivasan M, Gonzales CA, George C, Cevallos V, Mascarenhas JM, Asokan B et al (1997) Epidemiology and aetiological diagnosis of corneal ulceration in Madurai, south India. Br J Ophthalmol 81:965-971

4. Galarreta DJ, Tuft SJ, Ramsay A, Dart JK (2007) Fungal keratitis in London: microbiological and clinical evaluation. Cornea 26:1082-1086

5. Wright TM, Afshari NA (2006) Microbial keratitis following corneal transplantation. Am J Ophthalmol 142:1061-1062

6. Mahmoudi S, Masoomi A, Ahmadikia K, Tabatabaei SA, Soleimani M, Rezaie S et al (2018) Fungal keratitis: An overview of clinical and laboratory aspects. Mycoses 61:916-930

7. Thomas P, Kaliamurthy J (2013) Mycotic keratitis: epidemiology, diagnosis and management. Clin Microbiol Infect 19:210-220

8. Gopinathan U, Sharma S, Garg P, Rao GN (2009) Review of epidemiological features, microbiological diagnosis and treatment outcome of microbial keratitis: experience of over a decade. Indian J Ophthalmol 57:273-279

9. Spierer O, Dugar J, Miller D, O'Brien TP (2015) Comparative antifungal susceptibility analysis of Candida albicans versus non-albicans Candida corneal isolates. Cornea 34:576-579

10. Lalitha P, Sun CQ, Prajna NV, Karpagam R, Geetha M, O'Brien KS et al (2014) In vitro susceptibility of filamentous fungal isolates from a corneal ulcer clinical trial. Am J Ophthalmol 157:318-326

11. Gopinathan U, Garg P, Fernandes M, Sharma S, Athmanathan S, Rao GN (2002) The epidemiological features and laboratory results of fungal keratitis: a 10-year review at a referral eye care center in South India. Cornea 21:555-559

12. de Hoog GS, Guarro J, Gené J, Ahmed S, Al-Hatmi AMS, Figueras MJ, Vitale RG (2019) Atlas of Clinical Fungi, 3rd e-edition. Utrecht / Reus

13. Ng JK, Fraunfelder FW, Winthrop KL (2013) Review and update on the epidemiology, clinical presentation, diagnosis, and treatment of fungal keratitis. Curr Fungal Infect Rep 7:293-300

14. Ong HS, Fung SS, Macleod D, Dart JK, Tuft SJ, Burton MJ (2016) Altered patterns of fungal keratitis at a London Ophthalmic Referral Hospital: an eight-year retrospective observational study. Am J Ophthalmol 168:227-236

15. Adiguzel F, Cetin M, Kaya E, Simsek M, Gungor S, Sert EB (2020) Defining suitable areas for bioclimatic comfort for landscape planning and landscape management in Hatay, Turkey. Theor Appl Climatol 139:1493-1503

16. Kottek M, Grieser J, Beck C, Rudolf B, Rubel F (2006) World Map of the Köppen-Geiger climate classification updated. Meteorol Z 15:259-263

17. Semerci A, Celik AD (2017) Reflections of animal husbandry subsidies on dairy cattle enterprises: A case study of Hatay Province-Turkey. Journal of Tekirdag Agricultural Faculty 14:92-100

18. Iselin K, Baenninger P, Schmittinger-Zirm A, Thiel M, Kaufmann C (2017) Fungal Keratitis: A SixYear Review at a Tertiary Referral Centre. Klin Monbl Augenheilkd 234:419-425

19. Xie L, Zhong W, Shi W, Sun S (2006) Spectrum of fungal keratitis in north China. Ophthalmology 113:1943-1948 
20. Bharathi MJ, Ramakrishnan R, Vasu S, Meenakshi R, Palaniappan R (2003) Epidemiological characteristics and laboratory diagnosis of fungal keratitis. A three-year study. Indian J Ophthalmol 51:315-321

21. Microbial and parasitic infections of the cornea and sclera. In: American Academy of Ophthalmology. Basic and Clinical Science Course. External Disease and Cornea. Section 8. San Fransisco; 2003. p.1735

22. Srinivasan M (2004) Fungal keratitis. Curr Opin Ophthalmol 15:321-327

23. Punia RS, Kundu R, Chander J, Arya SK, Handa U, Mohan H (2014) Spectrum of fungal keratitis: clinicopathologic study of 44 cases. Int J Ophthalmol 7:114-117

24. Tanure MA, Cohen EJ, Sudesh S, Rapuano CJ, Laibson PR (2000) Spectrum of fungal keratitis at Wills Eye Hospital Philadelphia, Pennsylvania. Cornea 19:307-312

25. Srinivasan M, Gonzales CA, George C, Cevallos V, Mascarenhas JM, Asokan B et al (1997) Epidemiology and aetiological diagnosis of corneal ulceration in Madurai, south India. Br J Ophthalmol 81:965-971

26. Rodrigues MM, Laibson P (1975) Exogenous corneal ulcer caused by Tritirachium roseum. Am J Ophthalmol 80:804-806

27. Meyer RF, Hood Cl (1977) Fungus implantation with wooden intraocular foreign bodies. Ann Ophthalmol $9: 271-278$

28. Ebadollahi-Natanzi A, Arab-Rahmatipour G, Tabatabaei SA (2016) Prevalence of Fungal Keratitis (FK) in Patients with Corneal Ulcers in Farabi Eye Hospital, Tehran, 2011-2013. Asia Pac J Med Toxicol 5:9497

29. Thomas PA (2003) Fungal infections of the cornea. Eye 17:852-862

30. Bharathi MJ, Ramakrishnan R, Meenakshi R, Padmavathy S, Shivakumar C, Srinivasan M (2007) Microbial keratitis in South India: influence of risk factors, climate, and geographical variation. Ophthalmic epidemiol 14:61-69

31. Shah A, Sachdev A, Coggon D, Hossain P (2011) Geographic variations in microbial keratitis: an analysis of the peer-reviewed literature. Br J Ophthalmol 95:762-767

32. Alfonso EC, Cantu-Dibildox J, Munir WM, Miller D, O'Brien TP, Karp CL et al (2006) Insurgence of Fusarium keratitis associated with contact lens wear. Arch Ophthalmol 124:941-947

33. Khor WB, Aung T, Saw SM, Wong TY, Tambyah PA, Tan AL et al (2006) An outbreak of Fusarium keratitis associated with contact lens wear in Singapore. JAMA 295:2867-2873

34. Gaujoux T, Chatel MA, Chaumeil C, Laroche L, Borderie VM (2008) Outbreak of contact lens-related Fusarium keratitis in France. Cornea 27:1018-1021

35. Ma SK, So K, Chung PH, Tsang HF, Chuang SK (2009) A multicountry outbreak of fungal keratitis associated with a brand of contact lens solution: the Hong Kong experience. Int J Infect Dis 13:443-448

36. Rosa RH, Miller D, Alfonso EC (1994) The changing spectrum of fungal keratitis in South Florida. Ophthalmology 101:1005-1013

37. Burton MJ, Pithuwa J, Okello E, Afwamba I, Onyango JJ, Oates F et al (2011) Microbial keratitis in East Africa: why are the outcomes so poor? Ophthalmic Epidemiol 18:158-163 
38. Sekeroğlu HT, Yar K, Damar E, Uguz A, Yagmur M, Ersoz C et al (2010) Cytologically Diagnosed Fungal Keratitis: Clinical Features and Treatment Results. Turk J Ophthalmol 40:255-259

39. Yilmaz S, Ozturk I, Maden A (2007) Microbial keratitis in West Anatolia, Turkey: a retrospective review. Int Ophthalmol 27:261-268

40. Ritterband DC, Seedor JA, Shah MK, Koplin RS, McCormick SA (2006) Fungal keratitis at the New York eye and ear infirmary. Cornea 25:264-267

41. Sun RL, Jones DB, Wilhelmus KR (2007) Clinical characteristics and outcome of Candida keratitis. Am J Ophthalmol 143:1043-1045

42. Ho JW, Fernandez MM, Rebong RA, Carlson AN, Kim T, Afshari NA (2016) Microbiological profiles of fungal keratitis: a 10-year study at a tertiary referral center. J Ophthalmic Inflamm Infect 6(1):5

43. Keay LJ, Gower EW, lovieno A, Oechsler RA, Alfonso EC, Matoba A et al (2011) Clinical and microbiological characteristics of fungal keratitis in the United States, 2001-2007: a multicenter study. Ophthalmology 118:920-926

44. Eddy MT, Steinberg J, Richard G, Hassenstein A (2012) Schwerste kontaktlinsenassoziierte mykotische Keratitis [Severe contact lens-associated fungal keratitis]. Ophthalmologe 109:1106-1111

45. Ahearn DG, Zhang S, Stulting RD, Schwam BL, Simmons RB, Ward MA et al (2008) Fusarium keratitis and contact lens wear: facts and speculations. Med Mycol 46:397-410

46. Walther G, Stasch S, Kaerger K, Hamprecht A, Roth M, Cornely OA et al (2017) Fusarium Keratitis in Germany. J Clin Microbiol 55:2983-2995

47. Wong TY, Fong KS, Tan DT (1997) Clinical and microbial spectrum of fungal keratitis in Singapore: a 5year retrospective study. Int Ophthalmol 21:127-130

48. Prajna NV, Krishnan T, Mascarenhas J, Srinivasan M, Oldenburg CE, Toutain-Kidd CM et al (2012) Predictors of outcome in fungal keratitis. Eye (Lond) 26:1226-1231

49. Arunga S, Burton M (2018) Emergency management: microbial keratitis. Community Eye Health 31:6667

\section{Figures}

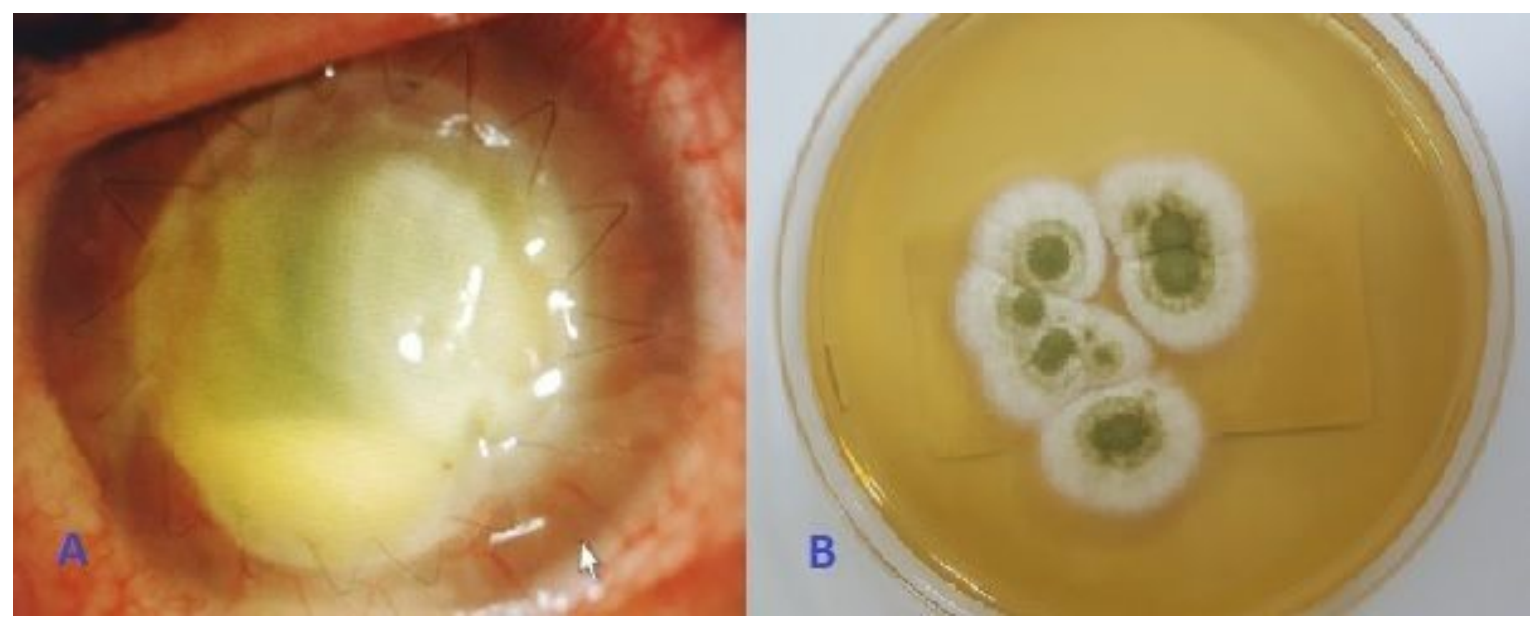


A. Fungal keratitis in the cornea of the left eye of an agricultural worker who underwent penetrating keratoplasty surgery 5 years ago. B. Aspergillus flavus growth was seen in the culture of corneal scraping sample. 